\title{
PENDETEKSIAN KERUSAKAN MODUL PADA TRANSMISI SATELIT PT. TELKOM RO PADANG MENGGUNAKAN BORLAND C++
}

\author{
Oleh : \\ Yenniwarti Rafsyam ${ }^{(1)}$, Jonifan ${ }^{(2)}$ \\ Staf Pengajar Teknik Elektro Politeknik Negeri Padang ${ }^{(1)}$ \\ Staf Pengajar Teknik Komputer Universitas Gunadarma Jakarta ${ }^{(2)}$.
}

\begin{abstract}
Detection of module damage at satellite transmission designed to be able to detect damage of transmission equipment especially at satellite transmission of PT. Telkom RO Padang. Module detected is a modem IDR (CDM 550). The system is an output of modem that will be an input at PC where its detection using interface $R S-232$ and $C++$. So that, from communications between modem with $P C$ resulting file error.txt. That file containing of damage status from modem. This Simulation expected to help the technician to detect the damage at satellite transmission equipment. This system more economical and give the best services to customers.
\end{abstract}

Keyword : Modem IDR CDM 550, C++, Interface RS-232, error.txt

\section{PENDAHULUAN}

PT. TELKOM RO Padang saat ini mengoperasikan Stasiun Bumi Besar (SBB) yang terletak di DLD-RO Padang. Transmisi satelitnya telah menghubungkan beberapa daerah seperti Padang - Medan yang menggunakan empat buah modem IDR, Padang Muaro Labuh, Padang - Sikakap, Padang - Tapan dan Padang - Balai Selasa dimana masing-masing menggunakan sebuah modem IDR. Modem IDR (Intermediate Data Rate) yang digunakan ialah pabrikan Comtech EF Data CDM 600.

Modem IDR merupakan suatu perangkat transmisi digital dengan kecepatan (bit rate) $64 \mathrm{Kbps}$ s/d $34 \mathrm{Mbps}$ yang dioperasikan pada stasiun bumi dengan menggunakan frekuensi yang berbeda-beda. Fungsinya untuk mengubah sinyal digital baseband dari perangkat tail link / sentral dalam bentuk sinyal IF yang dapat ditransmisikan melalui satelit, serta mengubah kembali sinyal IF dari transmisi satelit dalam bentuk sinyal digital baseband.

Ada beberapa perangkat yang mendukung kerja modem IDR di transmisi satelit RO Padang. Perangkat tersebut berupa, Up/Down Converter, HPA (High Power Amplifier), LNA (Low Noise Amplifier) dan antena. Selama ini, kerusakan yang terjadi pada perangkat transmisi satelit dideteksi oleh sistem alarm. Namun tidak diketahui perangkat mana yang mengalami kerusakan sehingga teknisi akan memeriksa satu persatu perangkat tersebut. Hal ini mungkin akan memakan waktu yang cukup lama dan layanan yang diberikan kepada pelanggan pun akan terganggu.

Untuk itulah dirancang suatu sistem yang dapat mendeteksi kerusakan modul atau perangkat yang terdapat pada transmisi satelit.

Dengan menggunakan sistem ini output dari perangkat satelit akan menjadi input pada PC. Artinya, jika suatu modul mengalami kerusakan, secara otomatis modul akan tertampil pada PC dengan 
tampilan yang mengidentifikasikan kalau modul tersebut sedang bermasalah.

Untuk pendeteksian, penulis menggunakan interface yang cocok dengan interface PC yaitu interface RS232. Dimana proses pendeteksian kerusakannya dilakukan sesuai dengan parameter yang terdapat pada data sheet modem.

Komunikasi antara PC dengan modem IDR menggunakan bahasa pemograman $\mathrm{C}++$ dengan interface-nya borland $\mathrm{C}++$. Hasil komunikasi tersebut menghasilkan file berektensi .txt yang diberi nama error.txt. File tersebut berisikan status kerusakan dari modem dan ditempatkan pada web server Apache agar nantinya terkoneksi dengan PHP sehingga pendeteksian dapat dilakukan. Modem yang digunakan dalam pendeteksian ialah modem CDM 550. Antara CDM 550 dengan CDM 600 tidak jauh berbeda. Perbedaannya terletak pada media konektor atau jumlah port yang digunakan.

Pembuatan

pendeteksian kerusakan modul pada transmisi satelit bertujuan untuk mendeteksi kerusakan yang terjadi pada transmisi satelit, sehingga dapat diketahui perangkat atau modul mana yang mengalami kerusakan. Dengan adanya sistem ini akan memudahkan teknisi dalam mengatasi kerusakan yang terjadi pada perangkat transmisi tersebut. Jadi pada saat alarm mengidentifikasikan adanya kerusakan, perangkat atau modul yang bermasalah akan langsung tertampil pada PC. Sehingga teknisi tidak perlu lagi memeriksa satu persatu perangkat yang ada pada transmisi satelit tersebut. Dengan demikian, gangguan komunikasi yang terjadi dapat ditangani secepat mungkin sehingga tidak menggangu pelanggan yang memanfaatkan pelayanan jasa yang diberikan oleh PT. Telkom.

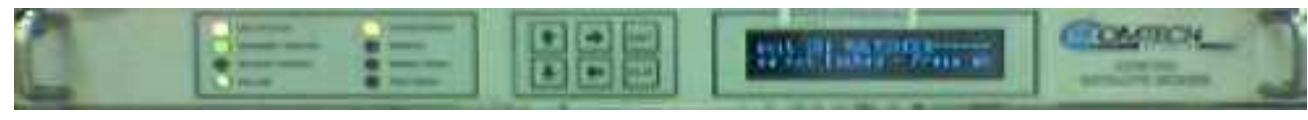

(a)

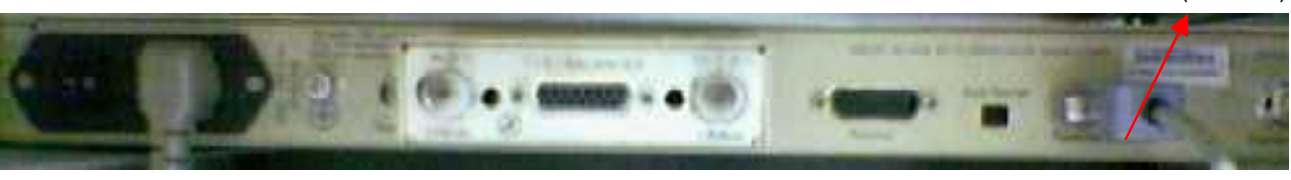

(b)

Gambar 1. Modem IDR CDM 550 (a) Panel Depan (b) Panel Belakang

Panel depan dari modem IDR ini terdiri dari sebuah display yang disebut dengan VFD (Vacuum Fluorescent Display), keypad, dan delapan buah lampu indikator. Seperti yang terlihat pada Gambar 1 (a). Untuk memasukkan data digunakan keypad dan pesannya akan tertampil di display pada VFD. Lampu indikator akan memberi tahu status dari modem tersebut. VFD akan menampilkan dua baris keterangan yang masing-masing terdiri dari 40 buah karakter. Pesan pada display tersebut akan tertampil dengan warna biru. Baris pertama akan menampilkan circuit ID sedangkan baris kedua menampilkan nilai Eb/No. Pesan tersebut akan selalu ditampilkan dan bergerak dari kanan ke kiri. Untuk keypad-nya terdiri dari enam buah tombol.

Pada panel belakang modem IDR terdiri dari beberapa konektor, seperti IEC line input connector, $R X$ dan TX IF connector, IDR alarm connector, IDI 
dan DDO connector, auxiliary serial connector, dan remote control connector yang dapat terlihat pada Gambar 1 (b).

IEC line connector terdiri dari switch ON/OFF dan memiliki dua buah fuse. $R X$ dan TX IF connector merupakan konektor tipe BNC $50 \Omega$ (female). IDR alarm connector menggunakan konektor DB-15 dengan tipe female (DB-15-F). IDI dan DDO connector, kedua konektor ini menggunakan BNC $75 \quad \Omega$ yang berfungsi sebagai Insert Data In dan Drop Data Out Port. Remote control connector menggunakan DB-9 dengan tipe male (DB-9-M) yang dapat dihubungkan dengan EIA-232 dan EIA485. Auxiliary serial connector merupakan port yang menggunakan konektor USB tipe B.

Modem IDR akan terhubung ke PC dengan menggunakan konektor port serial DB-9-F tepatnya pada port remote control. Seperti yang terlihat pada
Gambar 1 (b). Pada port inilah nantinya proses pendeteksian kerusakan dilakukan.

Komunikasi data antara modem dengan PC merupakan komunikasi serial. Dimana modem CDM 550 yang digunakan hanya memiliki port serial dan konektor BNC. Oleh karena itulah port serial dipilih sebagai interface agar dapat berkomunikasi dengan PC.

Peralatan yang menggunakan media serial port untuk berkomunikasi dibagi dalam dua kelompok, yaitu Data Communication Equipment (DCE) dan Data terminal Equipment (DTE). Contoh DCE ialah modem dan printer, sedangkan contoh DTE ialah terminal yang ada pada komputer.

Masing-masing pin-out serial port pada DB 9 menghasilkan sinyalsinyal untuk berkomunikasi. Hubungan konektor serial port dengan nama sinyalnya, dapat dilihat pada tabel 1 .

Table 1. Pin-Out Serial Port

\begin{tabular}{ccl}
\hline $\begin{array}{c}\text { DB-9 } \\
\text { Pin }\end{array}$ & Singkatan & \multicolumn{1}{c}{ Nama } \\
\hline Pin 3 & TD & Transmit Data \\
Pin 2 & RD & Receive Data \\
Pin 7 & RTS & Request To send \\
Pin 8 & CTS & Clear To Send \\
Pin 6 & DSR & Data Set Ready \\
Pin 5 & SG & Signal Ground \\
Pin 1 & CD & Carrier Detect \\
Pin 4 & DTR & Data Terminal Ready \\
Pin 9 & RI & Ring Indicator \\
\hline
\end{tabular}

Berikut ini merupakan penjelasan dari sinyal-sinyal serial port :

TD : Merupakan jalur output data serial

RD : Merupakan jalur input data serial

RTS : Memberitahu DCE bahwa UART siap bertukar data

CTS : Menunjukkan bahwa DCE siap bertukar data
DSR : Memberitahu UART bahwa DCE siap membangun hubungan
CD : Aktif jika DCE mendeteksi carrier dari DCE lain yang terhubung di ujung lain
DTR : Kebalikan dari DSR yang berfungsi untuk memberitahu DCE bahwa UART siap berhubungan
RI : Aktif jika DCE mendeteksi sinyal


Seperti yang telah dijelaskan sebelumnya, port yang digunakan adalah port serial dengan interface EIA-232, data ditransmisikan secara asynchronous, dengan menggunakan karakter ASCII. Oleh sebab itu, untuk melakukan hubungan dengan modem, sebaiknya mengikuti aturan yang telah ditentukan untuk modem. Pengaturan ini tercakup dalam suatu packet structure, yang terdiri atas start of packet, target address, address de-limiter, instruction code, code qualifier, dan optional arguments.

Selain interface EIA-232 digunakan juga bahasa pemograman $\mathrm{C}++$ untuk membantu proses pendeteksian dan pembuatan file error.txt.

\section{METODE PENELITIAN}

Pendeteksian diawali dengan mempersiapkan lingkungan program yang meliputi pengaturan interupsi dan pengaturan komunikasi. Pengaturan komunikasi terdiri atas pengaturan terhadap DLAB, LCR, FCR dan MCR. Setelah pengaturan komunikasi ini selesai maka proses pengiriman data dapat dilaksanakan. Selanjutnya pengirim mengirimkan data pada penerima. Oleh penerima data ini akan diproses untuk kemudian ditampilkan pada media hasil dari pengolahan data tersebut dalam hal ini adalah monitor PC. Secara umum diagram alirnya pada gambar 2 berikut :

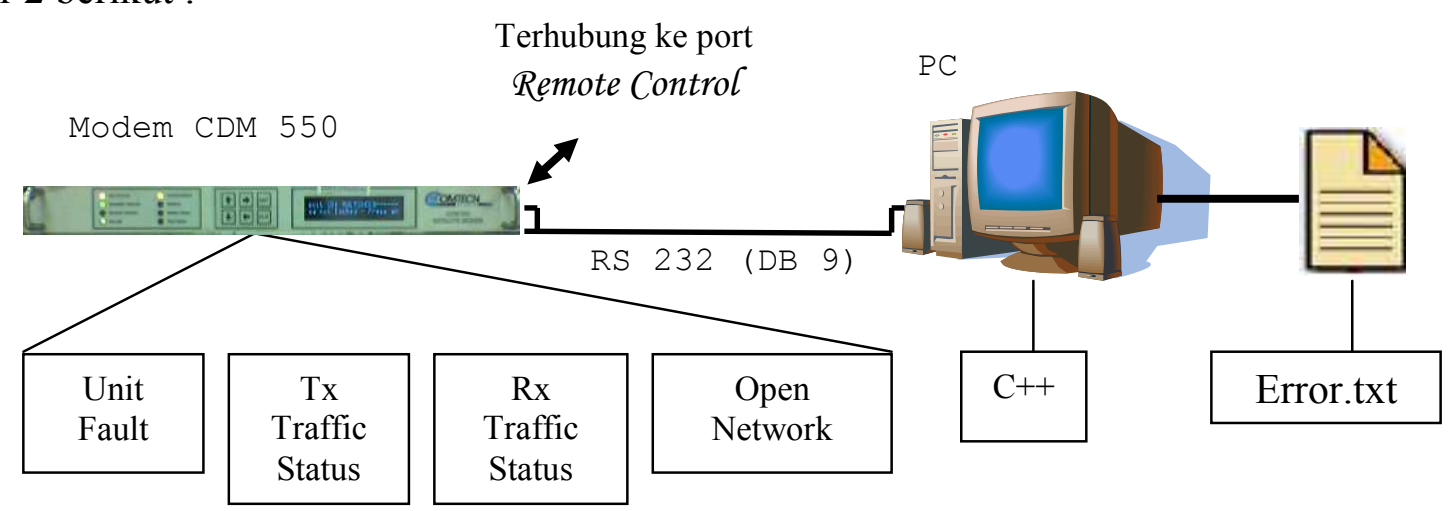

Gambar 3. Proses Pembuatan File error.txt yang revisi

Untuk melakukan komunikasi dengan modem perlu ditentukan terlebih dahulu port mana yang akan digunakan. Dari penjelasan sebelumnya port yang digunakan adalah port remote control. Port tersebut dipilih karena disanalah terdapat parameter-parameter yang mengindentifikasikan kerusakan modem. Parameter tersebut ialah : Unit Fault, Tx Traffic Status, Rx Traffic Status, dan Open Network. Kemudian untuk melakukan komunikasi, modem dengan PC dihubungkan dengan menggunakan kabel serial port DB-9.

\section{Gambar 2. Diagram Alir Program Pendeteksian}


Langkah awalnya, dilakukan pengalamatan port dengan cara mengatur beberapa parameter pada modem seperti; address : 0000 ; baud rate : 9600 dan interface RS-232. Kemudian dirancang program yang mengatur register-register yang digunakan untuk komunikasi tersebut. Program yang dirancang ini sudah mencakup seluruh program yang digunakan untuk komunikasi ini, termasuk program pembuatan file error.txt dengan menggunakan $\mathrm{C}++$. File tersebut ditempatkan pada sebuah folder apache, yang mana akan diterjemahkan oleh PHP.

\section{HASIL DAN PEMBAHASAN}

\section{Hasil}

Pendeteksian dilakukan dengan pengecekan address port, pengaturan register dan kemudian pendefenisian parameter-parameter modem yang nantinya dihasilkan file error.txt. seluruh proses tersebut dibuat dengan $\mathrm{C}++$ yang dieksekusi menggunakan Borland $\mathrm{C}++$.

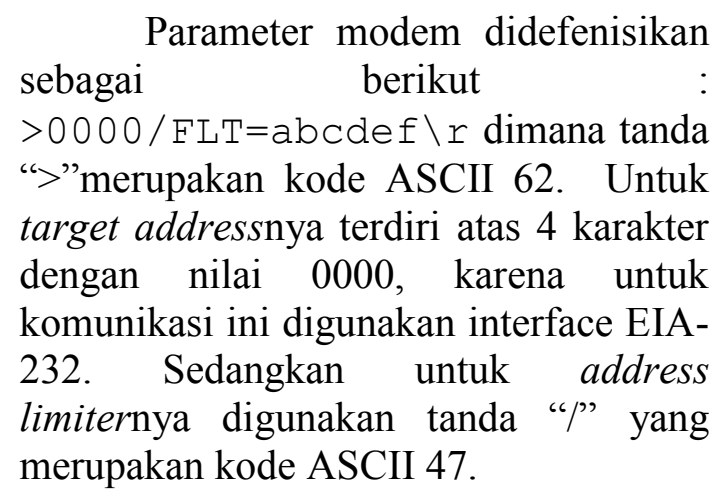

Kemudian pengaturan untuk instruction code. Instruction code ini terdiri atas 3 karakter alphabet yang mengindentifikasikan subjek pesan.
Sebagi contohnya, TFQ untuk transmit frequency, $\mathrm{RMD}$ untuk receive modulation type, FLT untuk fault, dan lain-lain.

Untuk code qualifier, digunakan tanda "?" yang digunakan untuk mengindikasikan bahwa ada error pada pesan yang dikirimkan oleh kontroler. Selanjutya pengaturan untuk optional arguments, yang terdiri dari karakter 0-9 (ASCII 48-57), A-Z (ASCII 65-90), periode (ASCII 46), spasi (ASCII 32), * (ASCII 42), + (ASCII 43), - (ASCII 45), / (ASCII 47) dan koma (ASCII 44).

Untuk membuktikan program yang telah dibuat dapat berjalan dengan baik atau tidak, maka dapat dilakukan pengujian dari program tersebut dengan jalan mengoperasikannya terlebih dahulu pada kompiler Borland $\mathrm{C}++$.

Langkah awal pengujian adalah dengan mengaktifkan kompiler Borland $\mathrm{C}++$, dan kemudian membuka file yang berisikan program simulasi yang akan diuji. Program simulasi ini disimpan dengan nama TEST.C.

$\begin{array}{llr}\text { Setelah } & \begin{array}{c}\text { tampilan } \\ \text { maka }\end{array} & \begin{array}{r}\text { program } \\ \text { dilakukan }\end{array}\end{array}$ pengkompilasian terhadap program tersebut. Jika tidak terdapat kesalahan atau error pada program maka proses kompile telah selesai dan akan terbuat sebuah file TEST.EXE. File inilah yang akan digunakan untuk pengujian program melalui command prompt pada windows. Bentuk tampilan dari file TEST.EXE tersebut dapat dilihat pada gambar 4 berikut : 


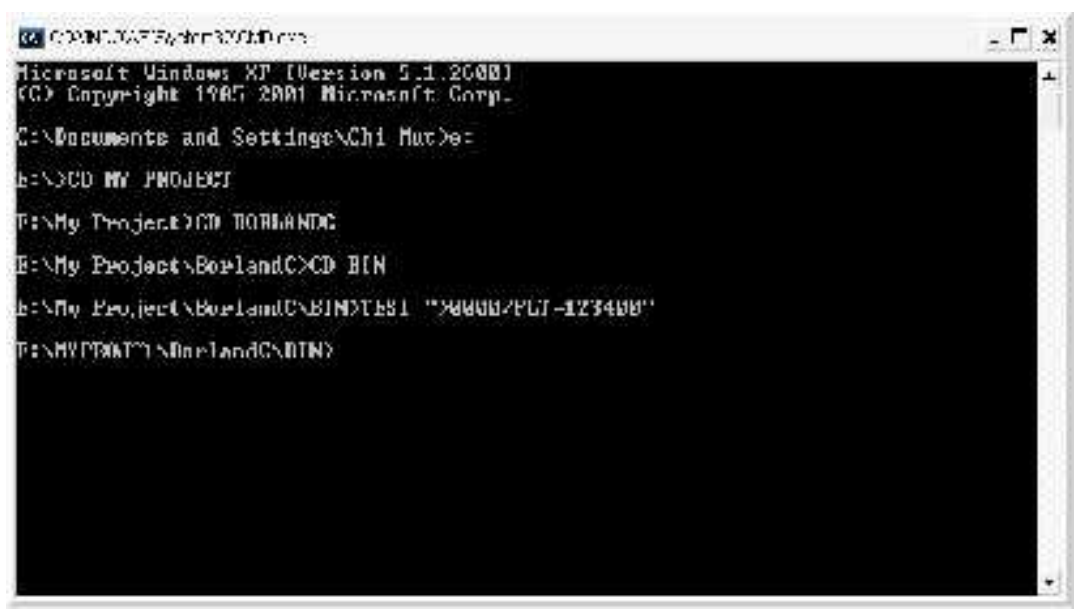

Gambar 4. Tampilan Menu CMD Dengan Kondisi Kerusakan Modul

Proses diatas akan menghasilkan suatu file yang berisikan status dari modul tersebut. Sesuai dengan yang dirancang dalam program, file tersebut dinamakan file ERROR.TXT. Isi dari file tersebut terlihat pada gambar 5 .

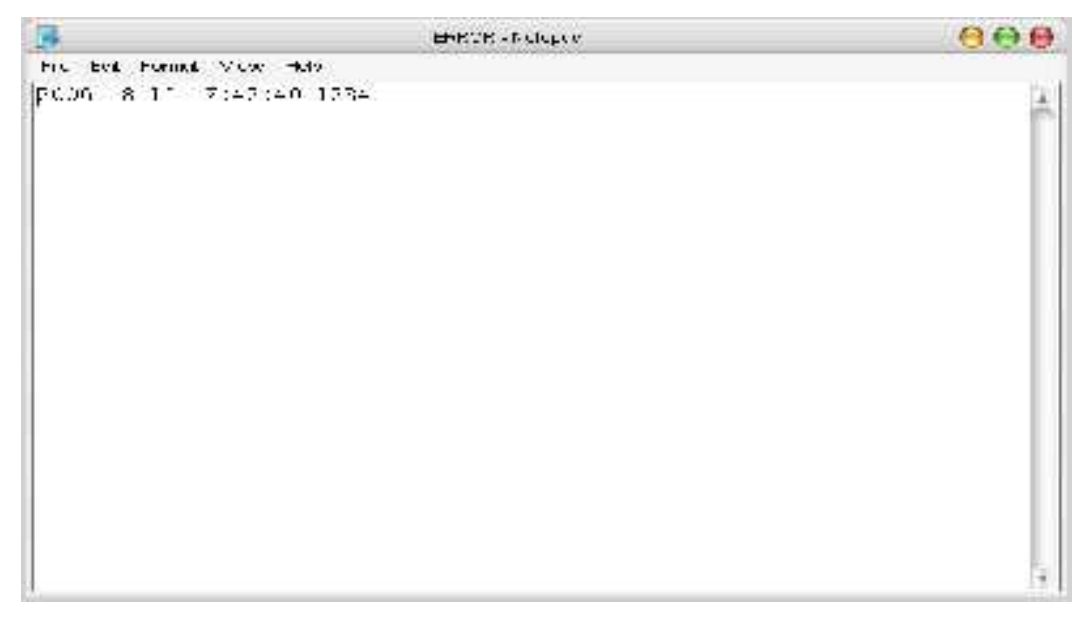

Gambar 5. Tampilan Isi Dari File error.txt

\section{Pembahasan}

Untuk dapat mengirimkan data, terlebih dahulu proses ini akan melalui beberapa tahap pengecekan. Yang pertama pengecekan address port yang berguna untuk mengecek alamat dari serial port. Apabila pengecekan ini tidak berhasil maka program tidak akan mengeksekusi data dalam artian program sudah berakhir. Tetapi bila pengecekan alamat ini berhasil, maka program akan mengecek komunikasi pada serial port tersebut. Pada pengecekan komunikasi ini akan dilakukan pengaturan terhadap DLAB, LCR, FIFO Control Register, DTR, RTS, dan OUT2. Setelah proses pengecekan ini berhasil maka proses pengiriman paket data dapat dilaksanakan. Dan diteruskan dengan proses pembacaan paket data, kemudian paket ini diterjemahkan. Setelah proses ini selesai, maka hasil dari proses ini akan ditampilkan pada layar. Proses ini akan berulang terus-menerus tergantung pada delay yang diberikan pada program. 
Untuk lebih jelasnya dapat dilihat pada

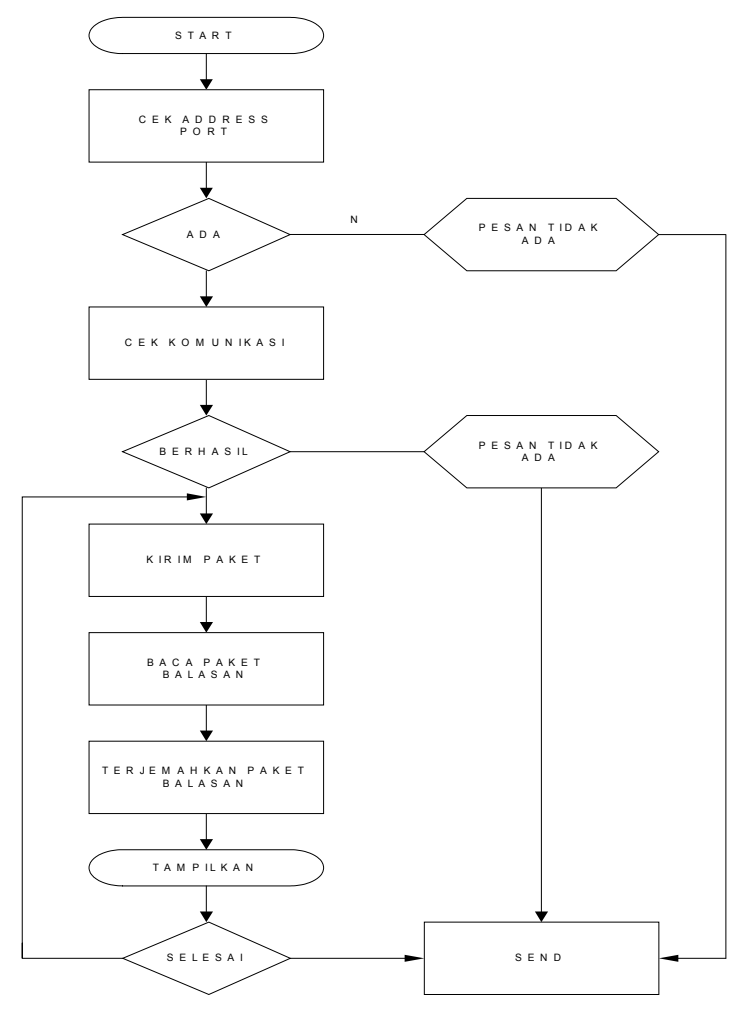

Gambar 6. Flow Chart Program Pendeteksian Kerusakan Modul

Pada saat program mulai berjalan, dia akan mencek apakah nilai i (int i) sudah sama dengan nol (0), apabila $\mathrm{i}=0$ maka program akan mencek lagi apakah i bernilai kecil dari panjang data yang telah ditentukan melalui program. Jika tidak maka program akan mencek lagi dari awal. Jika nilai i kecil dari panjang data maka program akan diteruskan untuk mengecek bit ke-5 dari register LSR. Jika bit ke-5 dari LSR ini bernilai 1, maka program akan mengirimkan data ke COM1. Seperti yang terlihat pada gambar 7 .

Setelah itu dilakukan penambahan terhadap nilai $i$ dan program akan kembali lagi pada tahap perbandingan nilai i dengan panjang data dan melakukan proses berikutnya. Hal ini akan terjadi berulang-ulang sesuai dengan jumlah perulangan dan lama gambar 6.

delay yang sudah diatur pada program. Jika nilai bit ke-5 LSR tidak bernilai 0 maka program akan terus menceknya sampai bit ini bernilai 1 untuk kemudian dilakukan proses selanjutnya.

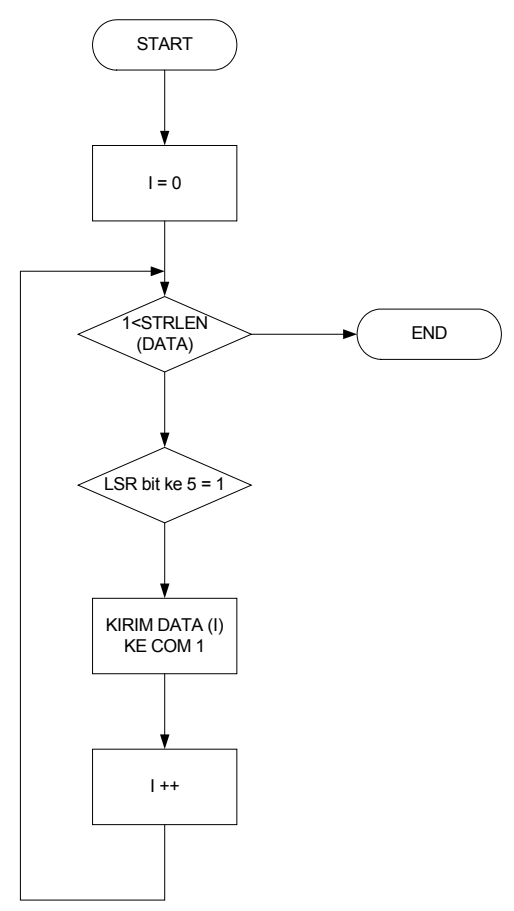

Gambar 7. Flow chart pengiriman data ke RS 232

\section{KESIMPULAN}

Simpulan dari proses pendeteksian ini, adalah sebagai berikut :

1. Pendeteksian ini dirancang untuk dapat memudahkan teknisi transmisi satelit PT. Telkom RO Padang dalam mendeteksi kerusakan pada perangkat transmisi mereka.

2. Dengan memanfaatkan pendeteksian ini bisa menghemat waktu dan tenaga sehingga teknisi akan langsung terfokus pada modul yang rusak. Dengan demikian kerusakan yang mungkin terjadi dapat diatas sesegera mungkin dan layanan yang 
diberikan kepada pelanggan tidak terganggu dalam waktu yang lama.

3. Pada perancangan program untuk sistem ini, program untk simulasi dan program untuk hubungan langsung dengan alat berbeda. Dimana pada program yang berhubungan langsung dengan alat, didalam perancangan program $\mathrm{C}++-$ nya dimasukkan parameterparameter kerusakan modem, sedangkan untuk program simulasi parameter tersebut dimasukkan ke dalam program PHP.

4. Dalam pembuatan program, yang terpenting ialah ketelitian seorang programer dalam merangkai dan menganalisa program-programnya. Sehingga setiap kode program yang digunakan dapat menjalankan fungsifungsi dengan baik dan benar.

\section{UCAPAN TERIMA KASIH}

Penulis mengucapkan terima kasih kepada Anna Syahrani yang telah membantu penulis dalam pengambilan data di PT. Telkom RO Padang. Dan juga kepada Kadin OPHAR Radio dan Satelit PT. Telkom RO Padang yang telah mengijinkan penulis untuk menggunakan peralatan transmisi satelit. Atas kerjasama pimpinan, karyawan dan teknisi PT. Telkom RO Padang penulis mengucapkan terima kasih.

\section{DAFTAR PUSTAKA}

http://dataaquisitonweb.com

http://dataaquisitionweb.com/datasheeta ndaquisitionweb

http://dataaquisitonweb.com/RS232stand artaquisitiondata

http://dataaquisitonweb.com/signalsdataa quisition 